\title{
Prediction of lignin content in ruminant diets and faecal samples using rapid analytical techniques
}

Article

Accepted Version

Lyons, G., Carmichael, E., McRoberts, C., Aubrey, A., Thomson, A. and Reynolds, C. K. (2018) Prediction of lignin content in ruminant diets and faecal samples using rapid analytical techniques. Journal of Agricultural and Food Chemistry, 66 (49). pp. 13031-13040. ISSN 0021-8561 doi: https://doi.org/10.1021/acs.jafc.8b03808 Available at https://centaur.reading.ac.uk/80754/

It is advisable to refer to the publisher's version if you intend to cite from the work. See Guidance on citing.

To link to this article DOI: http://dx.doi.org/10.1021/acs.jafc. $8 b 03808$

Publisher: American Chemical Society

All outputs in CentAUR are protected by Intellectual Property Rights law, including copyright law. Copyright and IPR is retained by the creators or other copyright holders. Terms and conditions for use of this material are defined in the End User Agreement. 


\section{CentAUR}

Central Archive at the University of Reading

Reading's research outputs online 
Prediction of lignin content in ruminant diets and faecal samples using rapid analytical techniques.

Gary Lyons ${ }^{*}$, , Eugene Carmichael ${ }^{\ddagger}$, Colin McRoberts ${ }^{\ddagger}$, Aurelie Aubry ${ }^{\dagger}$, Anna Thomson ${ }^{\S}$ and Christopher K. Reynolds ${ }^{\S}$.

${ }^{\dagger}$ Sustainable Agri-Food Sciences Division, Agri-Food and Biosciences Institute for Northern Ireland, Large Park, Hillsborough, BT26 6DR, UK

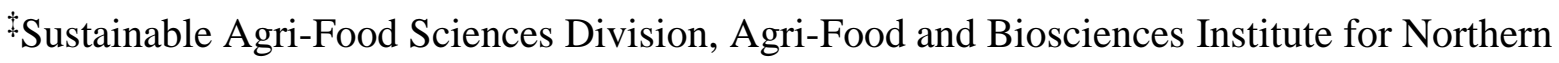
Ireland, Newforge Lane, Belfast, BT9 5PX, UK

${ }^{\S}$ Centre for Dairy Research, School of Agriculture, Policy and Development, University of Reading, PO Box 237, Earley Gate, Reading, RG6 6AR, UK

*Author to whom correspondence should be addressed. Tel.: +44 289268 1531; e-mail: gary.lyons@afbini.gov.uk 


\section{$1 \quad$ ABSTRACT}

2 The measurement of lignin content in ruminant diet and faecal samples is important for

3 digestibility studies, but it is typically time consuming and costly. The work reported

4 involved correlation of traditional wet chemistry data with that from three rapid instrumental

5 techniques, Fourier Transform Infrared spectroscopy (FTIR), Conventional

6 Thermogravimteric Analysis (TGA) and High Resolution TGA (MaxRes TGA) to predict

7 lignin content of diets and faeces from digestibility trials. Calibration and performance data

8 indicated that the FTIR model was acceptable for screening whilst the Conventional and

9 MaxRes TGA predictions were of high accuracy for quantitative analysis. Cross validation and model performance data revealed that MaxRes TGA provided the best performing predictive model. This work showed that MaxRes TGA can accurately predict lignin content in ruminant diet and faecal samples with distinct advantages over traditional wet chemistry, namely the requirement for small sample size, ease of sample preparation, speed of analysis and high sample throughput at considerably lower cost.

\section{KEYWORDS}

17 Lignin prediction, TGA, MaxRes TGA, FTIR, diets, faeces 


\section{INTRODUCTION}

Plant cell walls contain structural bio-macromolecules in the form of cellulose,

hemicellulose, lignin and pectins, in variable ratios dependent on tissue type, growth stage, harvest period, plant species and external factors such as environmental conditions, biotic and abiotic stress. ${ }^{1,2}$ The presence of lignin in the plant cell wall is associated with structural integrity, protection against damage and stress tolerance. ${ }^{3,4}$ Lignins have a complex molecular structure with a variety of inter-monomer linkages ${ }^{5}$ and cross-linking between the polysaccharides (cellulose and hemicellulose) and lignin via ester and ether linkages ${ }^{6}$ both of which inhibit forage digestibility in ruminants. ${ }^{7}$ The quantification of lignin is difficult not only because of its varying monomeric composition but also because lignins are covalently linked with cell wall carbohydrates, proteins, phenolics, or other compounds ${ }^{8}$ that may also affect digestibility.

Determination of lignin in animal feeds and forages is important as higher lignin content is generally associated with lower digestibility, leading to lower voluntary intakes 9,10 and reduced animal performance levels. Historically, lignin has been determined by gravimetric ${ }^{11}$ or spectrophotometric ${ }^{12}$ methods, both of which are time-consuming and costly, requiring lengthy wet chemical sample preparation techniques. Many other analytical methods have been utilised to determine the lignin content of plant lignocellulosic biomasses, in many cases aided by the availability of powerful multivariate analysis tools which allow accurate prediction models to be created. Techniques such as tissue colour difference following selective staining, ${ }^{13}$ the thioglycolic acid method, ${ }^{14}$ Near Infrared Spectroscopy, ${ }^{15}$ Fourier-transform Mid-Infrared Spectroscopy, ${ }^{16}$ solid state Nuclear Magnetic Resonance, ${ }^{17}$ Thermogravimetric Analysis, ${ }^{18}$ Analytical Pyrolysis ${ }^{19}$ and Fourier-transform Raman Spectroscopy ${ }^{20}$ have been reported in the literature as alternatives to the traditional gravimetric and spectrophotometric methods. 
The availability of not only rapid high throughput but also technologies with a high

degree of accuracy, which are widely applicable to measure lignin content in plant materials, is advantageous both for the scientific community and industry, where large sample numbers need to be analysed. For example, forage grass breeders, those processing lignocellulose (paper and pulping), the biomass for energy industry and animal feed producers, would benefit from more cost effective and less time consuming methods to estimate lignin content in feedstock materials. Our approach involved initial measurement of lignin in diet and faecal samples from sheep digestibility trials using a traditional wet chemistry technique. These diet and faecal samples were also analysed using three rapid instrumental techniques, namely Fourier Transform Infrared Spectroscopy (FTIR), Conventional Thermogravimetric Analysis (TGA) and High Resolution TGA (MaxRes TGA). FTIR spectroscopy is an established technique that provides detailed sample chemical information and can be used to characterise a range of components within samples. ${ }^{21,22}$ It can also be used for quantitative prediction of sample components. ${ }^{9,23}$ Conventional TGA uses constant heating profiles to determine decomposition rates of materials and compositional analysis. The decomposition steps associated with thermal degradation of plant biomass are not clearly separated and overlap with poor resolution. However this can be improved by lowering the heating rate during the decomposition steps using Hi-Res ${ }^{24}$ or MaxRes TGA methods resulting in a significant signal change. This increases the resolution of decomposition measurement because weight loss events that are in close proximity no longer overlap at a low heating rate. The resulting temperature programme is consequently composed of discrete dynamic segments. ${ }^{25} \mathrm{High}$ resolution TGA has been investigated by a number of authors to study a range of materials including inorganics, ${ }^{24}$ polymers and composites, ${ }^{26}$ lignocellulosic biomass ${ }^{27,28}$ and lignins ${ }^{29}$ amongst others. All of these authors reported an improvement in results when Hi-Res TGA was compared with Conventional TGA. The work reported here correlated wet chemical 
lignin results with data from each of the instrumental techniques, using Partial Least Squares Regression (PLSR) regression analysis, to create predictive models for lignin determination of ruminant diet and faecal sample sets.

\section{MATERIALS AND METHODS}

Diet and Faecal Samples. All in vivo procedures were licensed and monitored by the UK government Home Office under the Animal (Scientific Procedures) Act 1986. Diet and faecal samples for calibration development were obtained from two sheep feeding trials, the first at the University of Reading (UoR), UK, and the second at the Agri-Food and Biosciences Institute for Northern Ireland (AFBI), UK. The UoR experiment involved a total of thirty-six wether Texel x Mule sheep in an in vivo digestibility study that has been described previously. ${ }^{30}$ In brief, ninety perennial ryegrass (PRG) and clover mixture silages with a range of clover concentrations from 40 to $1000 \mathrm{~g} / \mathrm{kg}$ DM were each fed to three sheep in multiple 3x3 Latin Square designs with five day diet and faecal collection periods for determination of digestibility. Silages were obtained as large bales or chopped clamp material. Silages were chopped and mixed for uniformity and then frozen in vacuum sealed bags in quantities sufficient for daily feeding. Mature wether sheep were then fed each silage, thawed immediately before feeding, for three week periods (three wethers per silage) with five day total collection of faeces while sheep were housed in digestion crates for the last seven days of each period (two days adaptation to crates followed by five days of faecal collection). Sheep were fed silages for ad libitum intakes along with $20 \mathrm{~g} / \mathrm{d}$ of a mineral and vitamin mixture. Representative daily sub-samples of silages and corresponding total faecal collections were immediately added to a composite frozen sample for each five day collection period. A sample subset of ten of the silages fed and their respective faecal samples (one wether per silage) were selected for instrumental analyses based on low, medium and high clover diet contents to cover a range of silage clover concentrations. The AFBI experiment 
involved forty eight pregnant ewes from four breed types (Texel X, Highlander X, Belclare X and Lleyn X) offered three different diets (two grass silage diets and one all concentrate diet).

The animals were allocated to three diet treatment groups $(n=16$ ewes in each treatment), balanced for breed, live weight and condition score. Two sampling periods (seven days each) were undertaken, each with eight ewes from each diet group (i.e. twenty four ewes in each period). At each sampling period (six consecutive days), ewes were offered either grass silage 1, grass silage 2 or a diet based on concentrate (soya) and $50 \mathrm{~g} / \mathrm{d}$ of straw (to meet forage requirements). Experimental diets were fed for at least ten days before the start of each sampling period. Silages were fed on an ad libitum basis, with the levels of forage designed to ensure a refusal margin of $10 \%$. The total daily concentrate diet allowance was offered in two equal-sized meals at 09.30 and 16.30 daily to minimize the risk of acidosis. A sample of each diet and corresponding faecal sample from each breed fed that diet (three diet and twelve faecal samples) were selected for analysis.

Chemical Analyses. Frozen samples of diet and faeces were thawed and mixed before analysis for nitrogen $(\mathrm{N})$ content by the Kjeldahl method (Tecator Auto 1030 Kjeldahl Analyser, Foss Tecator, Sweden). Oven dried samples $\left(85^{\circ} \mathrm{C}\right.$ for $\left.72 \mathrm{~h}\right)$ were used to determine DM content using the volatile corrected oven dry matter (VCODM) method, ${ }^{31}$ before milling through a $1 \mathrm{~mm}$ screen for the following laboratory analyses. Ash content was measured by combustion of a $3 \mathrm{~g}$ sample in a muffle furnace at $600{ }^{\circ} \mathrm{C}$ for $6 \mathrm{~h}$. Neutral Detergent Fiber (NDF) and Acid Detergent Fiber (ADF) were determined sequentially without amylase ${ }^{32}$ and all values were expressed exclusive of residual ash. Acid detergent lignin (ADL) content was determined by solubilisation of cellulose with sulphuric acid. ${ }^{11}$

Conventional TGA. Conventional TGA combustion analysis was performed on a TGA/DSC1 Thermogravimetric Analyser (Mettler Toledo, Switzerland). Dried, milled diet and faeces samples ( $3 \mathrm{mg}$ ) were analysed in triplicate by heating dynamically from room 
temperature to $600{ }^{\circ} \mathrm{C}$ in alumina crucibles $(70 \mu \mathrm{L})$ at a heating rate of $20{ }^{\circ} \mathrm{C} \mathrm{min}{ }^{-1}$ under compressed air (BOC, UK) at a flow rate of $30 \mathrm{~mL} \mathrm{~min}^{-1}$. Peak weight loss (WL), peak combustion temperature (PT) and combustion char residue (RES) characteristics from thermogravimetric and first derivative $(d w / d t)$ weight loss curves were evaluated quantitatively using STARe (ver 9.30) Evaluation Software (Mettler Toledo, Switzerland).

MaxRes TGA. MaxRes TGA was performed using the same sample protocol and equipment as Conventional TGA but under a pyrolytic environment rather than an oxidative one. Pyrolysis was chosen to try to maximise the resolution between weight loss events, which is more difficult to achieve if oxygen is present in the reactive gas. Samples were heated from room temperature to $600{ }^{\circ} \mathrm{C}$ using a sample weight loss modulated variable heating rate programme set up in the MaxRes Analysis Toolkit. A dynamic heating rate of 10 ${ }^{\circ} \mathrm{C} \min ^{-1}$ was imposed from $40-125^{\circ} \mathrm{C}$. From $125-600{ }^{\circ} \mathrm{C}$ the base heating rate of $10{ }^{\circ} \mathrm{C}$ $\min ^{-1}$ was adjusted as follows: as the rate of weight loss exceeded $3 \mu \mathrm{g} \mathrm{s}^{-1}$ the heating rate was halved, if after a $12 \mathrm{~s}$ timeout the rate of weight loss still exceeded $3 \mu \mathrm{g} \mathrm{s}^{-1}$ the heating rate was halved again and so on to a minimum of $0.5^{\circ} \mathrm{C} \mathrm{min}-1$. As the rate of weight loss fell below $1 \mu \mathrm{g} \mathrm{s}^{-1}$ the heating rate doubled, if after a $12 \mathrm{~s}$ timeout the rate of weight loss remained below $1 \mu \mathrm{g} \mathrm{s}^{-1}$ the heating rate doubled again and so on until a maximum rate of 20 ${ }^{\circ} \mathrm{C} \min ^{-1}$ was reached. Samples were pyrolysed under nitrogen at a flow rate of $30 \mathrm{~mL} \mathrm{~min}^{-1}$ and similar data to the Conventional TGA runs were recorded.

FTIR Spectroscopy. The FTIR spectra of dried milled diet and faeces samples were obtained using a Spectrum One FTIR Spectrometer (Perkin Elmer Inc., USA) equipped with an attenuated total reflectance sampling device containing a diamond/ZnSe crystal. Spectra were scanned at room temperature in transmission mode $(\% \mathrm{~T})$ between $4000-650 \mathrm{~cm}^{-1}$, with 50 scans at a scan speed of $0.20 \mathrm{~cm} \mathrm{~s}^{-1}$ and a resolution of $4 \mathrm{~cm}^{-1}$. Samples were scanned in triplicate to obtain an average spectrum and the background spectrum was scanned under the 
same instrumental conditions. The spectra were acquired using Spectrum Software (version 10.4.1, Perkin Elmer Inc., USA), then base line corrected and normalised.

Statistical Analysis and Data Modelling. Diet and faeces chemical composition results, Conventional TGA and MaxRes weight loss data were analysed using Microsoft Excel to calculate Minima (Min), Maxima (Max) Mean and Standard Deviation (Sdev). Diet and faecal results for lignin contents measured by wet chemistry, continuous weight loss data from the Conventional and MaxRes TGA analyses, along with spectral absorbance data from FTIR analysis, were exported to "The Unscrambler" multivariate statistical software package (CAMO, Norway) for Principal Component Analysis (PCA) and Partial Least Squares Regression (PLSR) calibration development. PCA is a projection method that helps to visualize all of the information contained in a data table. PCA estimates in what respect one sample is different from another, which variables contribute most to this difference, and whether those variables contribute in the same way (i.e. are correlated) or independently from each other. It also enables detection of sample patterns, like any particular grouping. PLSR models both the $\mathrm{X}$ - and $\mathrm{Y}$-variables in a data set simultaneously to find the latent (or hidden) variables in $\mathrm{X}$ that will best predict the latent variables in Y. PLSR maximizes the covariance between X and Y. PLSR was performed using the guidelines presented in "The Unscrambler" user manual and the calibration models generated were full sized, data were centred and the suggested number of principle components for each was nine.

Because the sample set was relatively small, full cross validation was employed to facilitate maximum use of the available data for validation of the calibrations. Using full cross validation present in the Unscrambler, one sample was taken out of the calibration data set and the model was calibrated on the remaining data points. Then the values for the left-out sample were predicted and prediction residuals computed. The process was repeated by leaving out a different sample until every sample had been left out once. All prediction 
residuals were then combined to compute the validation residual variance. Calibration precision was evaluated by the coefficient of determination for calibration $\left(\mathrm{R}^{2} \mathrm{c}\right)$ and standard error of calibration (SEC). Predictive ability of calibrations ${ }^{33}$ was internally evaluated by coefficient of determination for cross validation $\left(\mathrm{R}^{2} \mathrm{cv}\right)$ and standard error of cross-validation (SECV). Calibration performance of the models was assessed using the RPD value defined as the ratio of performance to deviation. RPD value was based on the interpretation presented in ${ }^{34}$ where an RPD value of $<2.0$ is not suitable for prediction; values between $2.0-2.4$ are acceptable for screening purposes; values between $2.5-2.9$ are useful for quantification; and values $\geq 3.0$ indicate high accuracy for quantitative analysis.

\section{RESULTS AND DISCUSSION}

Composition of diet and faecal samples. Chemical composition of diet and faecal samples is represented in Table 1. UOR diets were more variable than those of the AFBI set with wider ranges for all parameters measured with the exception of DM. The concentrate diet was responsible for highest DM in the AFBI samples. The higher ADL and lower $\mathrm{N}$ content of the UoR diets could be attributed to the inclusion of a range of clover concentrations in these diets mixed with PRG. Faecal samples from both sets exhibited higher ash and ADL content when compared to diet samples. This would be expected due to the removal of digestable materials i.e. cellulose and hemicellulose, leaving indigestible components such as lignin and inorganic fractions as relatively larger proportions of the faeces. The means and ranges of DM for faeces were similar to their diets. The results indicated that the composition of diet and faecal sample sets were diverse and importantly, an extensive range of lignin contents were present in the samples for further analysis. It is also possible to infer that the AFBI diets were of higher potential digestibility when levels of DM, Ash and ADL were compared in the faecal samples from both sets of studies. 
of diet and faecal samples are presented in Figure 1. For the diet samples, two main

combustion events occurred around $300{ }^{\circ} \mathrm{C}$ and $450{ }^{\circ} \mathrm{C}$. Two main combustion events were also noted for faecal samples at temperatures close to $320^{\circ} \mathrm{C}$ and $490{ }^{\circ} \mathrm{C}$ with these events corresponding to biopolymer decomposition and char combustion respectively. The pyrolysis of cellulose has two temperature dependant pathways which can result in formation of carbonyl, carboxyl and hydroperoxide groups and the evolution of a range of low molecular weight products including $\mathrm{CO}, \mathrm{CO}_{2}$ and anhydrosugars whereas lignin is mainly charred to a carbonaceous residue ${ }^{35}$. The samples presented in Figure 1 displayed a range of lignin contents (diets $1.4-9.0 \%$, faeces $7.2-19.9 \%$ ) representing the variation in weight loss profiles in samples from the study and specific plots for individual samples have been depicted.

Weight loss (WL), peak combustion temperature (PT) and combustion char residue (RES) data for diet and faecal samples are displayed in Table 2. Mean WL 1 for UoR diets was higher than the AFBI samples, whilst PT1, WL 2 and PT 2 data were similar for both diet sets. Mean RES value was higher for the UoR diets. AFBI faecal samples had higher mean WL 1 and WL 2 values but similar PT 1 and PT 2 to those from UoR, and the mean RES value for UoR was twice that of the AFBI samples. The peak shoulders and split peaks $\left(100-350{ }^{\circ} \mathrm{C}\right.$ and $\left.400-450{ }^{\circ} \mathrm{C}\right)$ which were present on the diet DTG weight loss profiles

(Figure 1a), were either not as pronounced or are not present at all on the faecal samples (Figure 1b). This is because much of the hemicellulose and cellulose present in the diets had been degraded during ruminant digestion ${ }^{36}$ and this is also reflected by temperature shifts from 300 to $320{ }^{\circ} \mathrm{C}$ for PT 1 and 450 to $490{ }^{\circ} \mathrm{C}$ for PT 2 from diet to faecal analyses for both data sets. The higher PT's for the faecal samples were due to the relatively increased lignin content in comparison to the diets, which shifted the thermal degradation to higher 
temperatures. Cellulose content may also enhance the combustion characteristics and decomposition of lignin ${ }^{37}$. Using model compounds ${ }^{38}$ showed cellulose decomposes as a single peak due to its linear structure whereas hemicellulose and lignin decompose over wide temperature ranges due to their branched structures with peak temperatures in the order cellulose $<$ hemicellulose $<$ lignin. Variations in the shape, weight loss characteristics and peak combustion temperatures of diet and faecal samples are directly related to their chemical composition and in particular to their fiber fraction content. ${ }^{39,40}$

MaxRes TGA. MaxRes DTG pyrolysis weight loss curves of diets and corresponding faeces for individual representative samples with a range of lignin contents are illustrated in Figure 2. Diet and faecal samples produced four distinctive decomposition peaks between $130-350{ }^{\circ} \mathrm{C}$ that were associated with fiber fraction content. The decomposition peak at 130 ${ }^{\circ} \mathrm{C}$ was a common artefact due to a ramp up in the temperature of the furnace. The decomposition peaks at higher temperatures displayed variable height and width characteristics. These characteristics were expressed as WL, PT and RES data for diet and faecal samples and the quantitative data for the three largest decomposition peaks are presented in Table 3. Mean WL, PT and RES values for UoR and AFBI diets were generally similar, with the exception of WL 3 being higher for AFBI diets. The WL 4 on Table 3 was attributed to sample weight loss between the last major decomposition peak and the end temperature of $600{ }^{\circ} \mathrm{C}$. Comparable trends were noted for the UoR and AFBI faecal samples for mean WL and PT data, and again WL 3 was higher for AFBI samples, while RES was higher for the UoR samples (Table 3). Shifts to higher PT's were observed for the major decomposition peaks from the MaxRes analysis as had been found for the Conventional TGA combustions runs. The faecal peak temperatures were all higher than their corresponding diets with increases of $30-40{ }^{\circ} \mathrm{C}$ recorded due to the increased lignin content in comparison to the diets. 
244 TGA, if linked to mass spectrometry, may provide an opportunity to elucidate any variations

245 in structure between samples, or modifications to the biopolymers during digestion, by

246 measurement of the volatile gases evolved. This could be particularly applicable to lignin due

247 to the specificity of evolved gases such as the monomers which comprise the lignin structure.

248 In this study the lignin chemical structures were assumed to be relatively uniform across

249 samples since the diets are composed of the same initial material i.e. perennial

250 ryegrass/clover silages or mixtures of both. Therefore it is expected that lignin structure had

251 little impact in variations in analyses which are instead solely dependent on lignin content.

252 However, if necessary for example where a more varied range of diets were analysed, the

253 incorporation of $\mathrm{C}^{13} \mathrm{NMR}$ analysis would allow further elucidation of lignin structures ${ }^{45}$

254 from which it may be possible to correlate to MaxRes degradation peaks and indeed evolved

255 gases if the MaxRes TGA is linked to mass spectrometry providing a complementary

256 analysis.

FTIR Spectroscopy. Comparisons of the FTIR spectra of diets and faeces for

individual representative samples with a range of lignin contents are presented in Figure 3.

Major spectral bands were present at 3335 and $1040 \mathrm{~cm}^{-1}$ with antisymetric and symmetric vibration peaks observed from $2930-2850 \mathrm{~cm}^{-1}$. The prominent peak at $1756 \mathrm{~cm}^{-1}$ in the diets had shifted to $1732 \mathrm{~cm}^{-1}$ in the faecal samples. A range of peaks between $1640-1620$ $\mathrm{cm}^{-1}, 1550-1420 \mathrm{~cm}^{-1}, 1375-1310 \mathrm{~cm}^{-1}$ and $1240-1025 \mathrm{~cm}^{-1}$ were common in diet and faecal samples. Peak shifts and differences in peak intensities were noted when comparing the diets and faeces, and the peak at $873 \mathrm{~cm}^{-1}$ was more prominent and of greater intensity in the faecal samples. There was a notable reduction in the peak intensity at $1756 \mathrm{~cm}^{-1}$ in diet samples compared to the corresponding peak at $1732 \mathrm{~cm}^{-1}$ in the faeces, with differences in 
the number of peaks and their intensities also noted for the spectral bands from $1640-1025$ $\mathrm{cm}^{-1}$.

Major diet spectral bands at $3335 \mathrm{~cm}^{-1}$ and $1040 \mathrm{~cm}^{-1}$ (OH and C-O stretches) and peaks from $2930-2850 \mathrm{~cm}^{-1}$ were associated with cellulose. ${ }^{22}$ A peak at $2850 \mathrm{~cm}^{-1}(\mathrm{C}-\mathrm{H}$ stretch) and the peak at $1732 \mathrm{~cm}^{-1}$ were due to the presence of lignin and hemicellulose respectively. ${ }^{21,22}$ Hemicellulose peaks were present at $1640-1620 \mathrm{~cm}^{-1}$, bands between 1550 - $1420 \mathrm{~cm}^{-1}$ (aromatic C=C, C-H bends and C-H deformations) and at $1240 \mathrm{~cm}-1$ (aromatic C-O-C stretch) were from lignin, peaks between $1375-1310 \mathrm{~cm}^{-1}(\mathrm{C}-\mathrm{H}$ asymmetric deformation) and a peak/shoulder at $873 \mathrm{~cm}^{-1}$ were associated with cellulose. ${ }^{21}$ Reduced intensity at $1732 \mathrm{~cm}^{-1}$ indicated lower faecal hemicellulose. ${ }^{22}$ The variation in spectral intensities and peak shifts from $1640-1172 \mathrm{~cm}^{-1}$ were due to degradation of dry matter, particularly hemicellulose and cellulose during digestion, and the relative increase in faecal lignin concentration due to its poor digestibility. ${ }^{41}$

Statistical Analysis and Data Modelling. Calibration and validation statistics along with RPD values for the predictive models for each analytical technique are displayed in Table 4. The calibration and cross validation data for models derived from each technique indicated excellent precision and predictive ability, and that all models could be used to predict lignin content of the diet and faecal samples. Best calibration statistics were obtained using the Conventional TGA data $\left(\mathrm{R}^{2} \mathrm{c} 0.98\right.$ and SEC 1.08) while best cross validation statistics were produced from the MaxRes TGA results ( $\mathrm{R}^{2} \mathrm{cv} 0.95$ and SECV 1.64). Calibration performance of the prediction equations was assessed using the RPD value, which revealed that the FTIR model (RPD 2.20) did not perform as well as the Conventional and MaxRes TGA models (RPD 3.05 and 3.38 respectively). Using the interpretation presented in, ${ }^{34}$ the FTIR prediction model would be acceptable for sample screening while the Conventional and MaxRes TGA predictions could be regarded as highly accurate and 
could be used for quantitative analysis. The combination of best cross validation statistics and highest RPD value indicated that the MaxRes TGA technique provided the best performing predictive model of the three rapid analytical methods studied. Multivariate analysis results represented by PCA and calibration model regression coefficients are displayed in Figure 4a and Figure 4b respectively. PCA of MaxRes TGA continuous weight loss data (Figure 4a) produced two distinct clusters for diet and faecal samples based on the differences in chemical composition, including lignin content. The first two principle components explained $92 \%$ of the sample variation. While it is accepted that lignin degradation occurs across a wide temperature range, the calibration model regression coefficients (Figure $\mathbf{4 b}$ ) showed the most influential data points along the temperature scale for lignin prediction $\left(160-490{ }^{\circ} \mathrm{C}\right)$.

Regression coefficients show how each variable is weighted when predicting a particular $\mathrm{Y}$ response. In a regression model equation, regression coefficients are the numerical coefficients that express the link between variation in the predictors and variation in the response. The data points corresponded with the areas of maximum weight loss on MaxRes DTG thermograms (Figure 2) and were consistent with the view that thermal degradation of lignin involves multi-step reactions that occur over a temperature range. ${ }^{29}$

Other studies have used Near Infrared Spectroscopy (NIRS) to quantify lignin content in similar samples. The calibration produced by ${ }^{42}$ was of poorer quality $\left(\mathrm{R}^{2} \mathrm{cv} 0.77\right.$; RPD 2.1$)$ than those developed in our work, while those reported by ${ }^{43,44}$ could be regarded as being of similar or better quality $\left(\mathrm{R}^{2} \mathrm{cv} 0.94\right.$; RPD 4.0 and $\mathrm{R}^{2} \mathrm{cv} 0.95$; RPD 4.4 respectively) than ours. All of these studies used larger sample sets $(n=84-299)$. A Hi-Res TGA calibration model created for lignin prediction in willow biomass ${ }^{28}$ reported an $\mathrm{R}^{2} \mathrm{c}$ of 0.76 , while lignin calibrations developed by ${ }^{1}$ for switchgrass using FTIR and Pyrolysis Molecular Beam Mass Spectrometry (PyMBMS), reported statistics of $\mathrm{R}^{2} \mathrm{cv} 0.96$ and $\mathrm{R}^{2} \mathrm{cv} 0.94$ respectively. In conclusion, this work has demonstrated that the three rapid analytical technologies 

investigated can all accurately predict lignin content of ruminant diet and faecal samples.

They have distinct advantages over many of the conventional methodologies in use, namely the requirement for small sample size, ease of sample preparation, automation, speed of analysis and high sample throughput at considerably lower cost. The reported research has given an initial indication of the positive potential for the techniques studied to predict lignin content of a relatively small sample set. Increasing the diet and faecal sample set sizes should improve the statistics and predictive ability of the equations that were developed. Follow on work to look at a wider range of diets and corresponding faecal samples and to externally validate the models with blind samples would be important for future application of the approaches. The addition of a mass spectrometer to the TGA equipment using the MaxRes method for evolved gas analysis, would enable detailed characterisation of resolved peaks, increasing the understanding of the thermal decomposition of biomass under pyrolytic conditions.

\section{ABBREVIATIONS USED}
ADF - Acid Detergent Fiber

AFBI - Agri-Food and Biosciences Institute

DM - Dry Matter

DTG - Derivative Thermogravimetry

FTIR - Fourier Transform Infrared

Hi-Res TGA - High Resolution Thermogravimetric Analysis

Max-Res TGA - Maximum Resolution Thermogravimetric Analysis

Max - Maximum value 
Min - Minimum value

340

NDF - Neutral Detergent Fiber

341 PCA - Principle Component Analysis

342 PLSR - Partial Least Squares Regression

343 PRG - Perennial Ryegrass

344 PT - Peak Temperature

345 RES - TGA Combustion Char Residue

346 RPD - Ratio of Prediction to Deviation

$347 \quad R^{2} c$ - Coefficient of determination for calibration

$348 \quad \mathrm{R}^{2} \mathrm{cv}$ - Coefficient of determination for cross validation

349 Sdev - Standard Deviation

350 SEC - Standard Error of Calibration

351 SECV - Standard Error of Cross Validation

352 TGA - Thermogravimetric Analysis

353 UoR - University of Reading

354 WL - Thermogravimetric Weight Loss

\section{ACKNOWLEDGEMENT}

356 The authors would like to acknowledge the assistance of Prof Shekhar Sharma (AFBI,

357 retired) for his help with the multivariate analyses. 
360

361

362

363

364

365

366

367

368

369

370

371

372

373

374

375

376

377

378

379

(1) Mann, G. J.; Labbe, N.; Sykes, R. W.; Gracom, K.; Kline, L.; Swamidoss, I. M.; Burris, J.

N.; Davis, C.; Stewart Jr. N. Rapid assessment of lignin content and structure in switchgrass

(Panicum virgatum L.) grown under different environmental conditions. Bioenergy Res.

2009, 2, 246-256.

(2) Boerjan, W.; Ralph, J.; Baucher M. Lignin biosynthesis. Annu. Rev. Plant Biol. 2003, 54, 519-546.

(3) Liu, Q.; Luo, L,; Zheng, L. Lignins: Biosynthesis and biological functions in plants. Int. J. Mol. Sci. 2018, 19 (2), 335-350.

(4) Moura J.C.M.S., Bonine C.A.V., Viana J.D.O.F., Dornelas M.C., Mazzafera P. Abiotic and biotic stresses and changes in the lignin content and composition in plants. J. Integr. Plant Biol. 2010, 52, 360-376.

(5) Brown, S.A. Lignin and tannin biosynthesis. In Biochemistry of Phenolic Compounds; Harborne J.B. Ed.; Academic Press, London, UK, 1964, pp 361.

(6) Hartley, R.D; Jones, E.C. Phenolic components and digestibility of cell walls of grass and legume species. Phytochem. 1977, 16, 1531-1534.

(7) Vogel, K. P.; Jung, H. J. G. Genetic modification of herbaceous plants for feed and fuel. Crit. Rev. Plant Sci. 2001, 20, 15-49.

(8) Brinkman, k.; Blaschke, L.; Polle A. Comparison of different methods for lignin determination as a basis for calibration of Near-Infrared Reflectance Spectroscopy and implications of lignoproteins. J. Chem. Ecol. 2002, 28, 2483-2501. 
380

381

382

383

384

385

386

387

388

389

390

391

392

393

394

395

396

397

398

399

400

401

(9) Lyons, G.; Sharma, S.; Aubry, A.; Carmichael, E.; Annett, R. A preliminary evaluation of the use of mid infrared spectroscopy to develop calibration equations for determining faecal composition, intake and digestibility in sheep. Animal Feed Sci. Tech. 2016, 221, 44-53.

(10) Allen, M. S. Physical constraints on voluntary intake of forages by ruminants. J. Anim. Sci. 1996, 74, 3063-3075.

(11) van Soest, P.J. Use of detergents in the analysis of fibrous feeds. II. A rapid method for the determination of fiber and lignin. J. A.O.A.C. 1963, 46, 830-835.

(12) Morrison, I. M. A semi-micro method for the determination of lignin and its use in predicting the digestibility of forage crops. J. Sci. Food Agric. 1972, 23, 455-463.

(13) Stange Jr, R. R.; McDonald, R. E. A simple and rapid method for determination of lignin in plant tissues - its usefulness in elicitor screening and comparison to the thioglycolic acid method. Postharv. Biol. Tech. 1999, 15, 185-193.

(14) Bostock, R. M.; Stermer, B.A. Perspectives on wound healing in resistance to pathogens. Annu. Rev. Phytopathol. 1989, 27, 343-371.

(15) Wetzel, D. L. Contemporary near-Infrared instrumentation. In: Williams P, Norris K, editors. Near infrared technology in the agricultural and food industries. St. Paul, Minnesota, USA. American Association of Cereal Chemists, Inc.; 2001, 129-144.

(16) Allison, G .G.; Thain, S. C.; Morris, P.; Morris, C.; Hawkins, S.; Hauck, B.;

Barraclough, T.; Yates, N.; Shield, I.; Bridgewater, A. V.; Donnison, I. S. Quantification of hydroxycinnamic acids and lignin in perennial forage and energy grasses by Fouriertransform infrared spectroscopy and partial least squares regression. Bioresour. Technol. $\mathbf{2 0 0 9 , 1 0 0 , ~ 1 2 5 2 - 6 1 . ~}$ 
402

403

404

405

406

407

408

409

410

411

412

413

414

415

416

417

418

419

420

421

422

423

424

(17) Fu, L.; McCallum, S. A.; Miao, J.; Hart, C.; Tudryn, G. J.; Zhang, F.; Linhardt, R. J.

Rapid and accurate determination of the lignin content of lignocellulosic biomass by solidstate NMR. Fuel, 2015, 141, 39-45.

(18) Carrier, M.; Loppinet-Serani, A.; Denux, D.; Lasnier, J-M.; Ham-Pichavant, F.; Cansell, F.; Aymonier, C. Thermogravimetric analysis as a new method to determine the lignocellulosic composition of biomass. Biomass Bioenergy. 2011, 35, 298-307.

(19) Alves, A.; Schwanninger, M.; Pereira, H.; Rodrigues, J. Analytical pyrolysis as a direct method to determine the lignin content in wood. J. Anal. Appl. Pyrolysis. 2006, 76, 209-213.

(20) Ona, T.; Sonoda, T.; Ito, K.; Shibata, M.; Kato, T.; Ootake, Y. Non-destructive determination of wood constituents by Fourier-transform Raman spectroscopy. J. Wood. Chem. Technol. 1997, 17, 399-417.

(21) Kondo, T.; Sawatari, C. A Fourier transform infra-red spectroscopic analysis of the character of hydrogen bonds in amorphous cellulose. Polymer, 1996, 37, 393-399.

(22) Liu, C.F.; Xu, F.; Sun, J.X.; Ren, J.L., Curling, S.; Sun, R.C.; Fowler, P.; Baird, M.S. Physicochemical characterisation of cellulose from perennial ryegrass leaves (Lolium perenne). Carbohydr. Res. 2006, 341, 2677-2687.

(23) Moorby, J.M.; Fraser, M.D.; Parveen, I.; Lee, M.R.F.; Wold, J.P. Comparison of 2 highthroughput spectral techniques to predict differences in diet composition of grazing sheep and cattle. J. Anim. Sci. 2010, 88, 1905-1913.

(24) Gill, P. S.; Sauerbrunn, S. R.; Crowe, B. S. High resolution thermogravimetry. J. Therm. Anal. 1992, 38, 255-266.

(25) Riesen, R. Adjustment of heating rate for maximum resolution in TG and TMA (MaxRes). J. Therm. Anal. 1998, 53, 365-374. 
425

426

427

428

429

430

431

432

433

434

435

436

437

438

439

440

441

442

443

444

445

446

(26) Salin, M.; Seferis, J. C. Kinetic analysis of High-resolution TGA variable heating rate data. J. Appl. Polym. Sci. 1993, 5, 847-856.

(27) Cheng, K.; Winter, W. T.; Stipanovic, A. J. A modulated-TGA approach to the kinetics of lignocellulosic biomass pyrolysis/combustion. Polym. Degrad. Stab. 2017, 97, 1606-1615.

(28) Serapligia, M. J.; Cameron, K. D.; Stipanovic, A. J.; Smart, L. B. Analysis of biomass composition using high-resolution thermogravimetric analysis and percent bark for the selection of shrub willow bioenergy crop varieties. Bioenerg. Res. 2009, 2, 1-9.

(29) Kubo, S.; Kadla, J. F. Thermal decomposition study of isolated lignin using temperature modulated TGA. J. Wood Chem. 2008, 28, 106-121.

(30) Thomson, A. L.; Humphries, D. J.; Rymer, C.; Archer, J.; Grant, N.; Reynolds, C. K. Assessing the accuracy of current near infra-red reflectance spectroscopy analysis for fresh grass-clover mixture silages and development of new equations for this purpose. Animal Feed Sci. Tech. 2018, 239, 94-106.

(31) Porter, M. G.; Murray, R. S. The volatility of components of grass silage on oven drying and the inter-relationship between dry-matter content estimated by different analytical methods. Grass and Forage Sci. 2001, 56, 405-411.

(32) van Soest, P.; Robertson, J.; Lewis, B. Methods for dietry fibre, neutral detergent fibre and Polymer, 41, 2647-2656.non-starch polysaccharides in relation to animal nutrition. $J$. Dairy Sci, 1991, 74, 3583-3597.

(33) Stuth, J.; Jama, A.; Tolleson, D. Direct and indirect means of predicting forage quality through near infrared reflectance spectroscopy. Field Crops Res. 2003, 84, 45-56.

(34) Williams, P. Tutorial: the RPD statistic; a tutorial note. NIR News, 2001, 25, 22-26. 
447 (35) Shafizadeh, F. Introduction to pyrolysis of biomass. J. Anal. Appl. Pyrolysis.1982, 3, $448 \quad 283-305$.

449 (36) Weimer, P. J. Cellulose degradation by ruminal microorganisms. Crit. Rev Biotech. 450 1992, 12, 189-223.

451

452

453

454

455

456

457

458

459

460

461

462

463

464

465

466

467

(37) Gani, A.; Naruse, I. Effect of cellulose and lignin content on pyrolysis and combustion characteristics for several types of biomass. Ren. Energy. 2007, 32, 649-661

(38) Kok, M. V.; Ozgur, E. Characterization of lignocellulose biomass and model compounds by thermogravimetry. Energy Sources, Part A: Recovery, Utilization, and Environmental Effects. 2017, 39, 134-139.

(39) Lyons, G. A.; McRoberts, W. C.; Sharma, H. S. S.; McCormack, R. A.; Carmichael, E.; McCall, R. D. Rapid analysis of purified cellulose extracted from perennial ryegrass (Lolium perenne) by instrumental analysis. Bioresour. Technol. 2013, 146, 184-191.

(40) Marvin, H.J.P.; Krechting, C.F.; van Loo, E.N.; Snijders, C.H.A. Potential of thermal analysis to estimate chemical composition and in vitro fermentation characteristics of maize. J. Agric. Food Chem. 1996, 44, 3467-3473.

(41) Alemdar, A.; Sain, M. Isolation and characterisation of nanofibers from agricultural residues - wheat straw and soy hulls. Bioresour. Technol. 2008, 99, 1664-1671.

(42) Fanchone, A.; Boval, M.; Lecomte, P.; Archimède, H. Faecal indices based on near infrared spectroscopy to assess intake, in vivo digestibility and chemical composition of the herbage ingested by sheep (crude protein, fibres and lignin content). J. Near Infrared Spec. 2007, 15, 107-113. 

mining old digestibility trials for nutritional monitoring in confined goats with aids of near infra-red spectroscopy. Small Rum. Res. 2008, 77, 146-158.

471 (44) Decandia, M.; Giovanetti, V.; Boe, F.; Scanu, G.; Cabbidu, A.; Molle, G.; Cannas, A.;

472 Landau, S. Faecal NIRS to assess the chemical composition and nutritive value of dairy sheep 473 diet. In: Proceedings of the $12^{\text {th }}$ FAO-CIHEAM meeting on sheep nutrition, 11-13 October, 474 2007, Thessaloniki, Greece.

475 (45) Capanema, E.; Balakshin, M.; Kadla, J. A comprehensive approach for quantative lignin 476 characterization by NMR spectroscopy. J. Agric. Food Chem. 2004, 52, 1850-1860

\section{FUNDING}

478 The authors wish to thank the Department of Agriculture, Environment and Rural Affairs for

479 Northern Ireland for funding Evidence and Innovation Project 15-1-11 for the AFBI work 480 and AHDB Dairy Forages, Soils and Grasslands Research Partnership for funding the UoR 481 sheep digestibility work. 


\section{FIGURE CAPTIONS}

Figure 1. Conventional TGA derivative thermogravimetric (DTG) plots of weight loss profiles $(d w / d t)$ against increasing temperature for representative samples of (a) diets and (b) faeces with a range of lignin contents indicated by coloured lines.

Figure 2. MaxRes TGA derivative thermogravimetric (DTG) plots of weight loss profiles $(d w / d t)$ against increasing temperature for representative samples of (a) diets and (b) faeces with a range of lignin contents indicated by coloured lines.

Figure 3. FTIR spectra for representative samples of (a) diets and (b) faeces with a range of lignin contents indicated by coloured lines. Plots show percentage transmittance (\%T) against change in wavelength $\left(\mathrm{cm}^{-1}\right)$ with major peak markers included.

Figure 4. Multivariate analysis of MaxRes TGA continuous weight loss data showing (a) Principle Component Analysis with diet and faecal samples separating in to two distinct clusters and (b) calibration model regression coefficients showing the most important data points along the temperature scale for lignin prediction with both positive and negative influences. 
Table 1. Chemical Composition of Diet and Faecal Samples Used to Develop Calibration Equations From Sheep Feeding Trials at UoR and AFBI. ADL Content of Diet and Faecal Samples Used for Calibration Validation is Also Shown. Minima, Maxima, Means and Standard Deviations are Presented.

\begin{tabular}{|c|c|c|c|c|c|c|c|c|}
\hline Parameter & Min & Max & Mean & Sdev & Min & Max & Mean & Sdev \\
\hline & \multicolumn{4}{|c|}{ UoR Diets $(n=10)$} & \multicolumn{4}{|c|}{ AFBI Diets $(n=3)$} \\
\hline $\mathrm{DM}(\mathrm{g} / \mathrm{kg})$ & 222.0 & 592.1 & 410.0 & 148.6 & 299.4 & 872.4 & 511.4 & 314.2 \\
\hline Ash (g/kg DM) & 68.6 & 128.3 & 98.4 & 27.2 & 89.3 & 103.0 & 94.6 & 7.4 \\
\hline$N(g / k g ~ D M)$ & 4.2 & 17.5 & 9.2 & 4.5 & 20.8 & 27.6 & 24.3 & 3.4 \\
\hline $\mathrm{ADF}(\mathrm{g} / \mathrm{kg} \mathrm{DM})$ & 228.6 & 386.3 & 323.0 & 47.5 & 322.9 & 372.1 & 343.1 & 25.7 \\
\hline $\mathrm{NDF}(\mathrm{g} / \mathrm{kg} \mathrm{DM})$ & 299.2 & 521.5 & 419.1 & 80.1 & 552.2 & 577.5 & 563.9 & 12.8 \\
\hline \multirow[t]{2}{*}{$\operatorname{ADL}(\% \mathrm{DM})$} & 2.1 & 9.0 & 5.4 & 2.4 & 1.4 & 2.5 & 2.1 & 0.5 \\
\hline & \multicolumn{4}{|c|}{$\underline{\text { UoR Faeces }(n=10)}$} & \multicolumn{4}{|c|}{$\underline{\text { AFBI Faeces }(n=12)}$} \\
\hline $\mathrm{DM}(\mathrm{g} / \mathrm{kg})$ & 222.0 & 671.2 & 422.3 & 144.6 & 227.6 & 363.7 & 293.7 & 41.3 \\
\hline Ash (g/kg DM) & 90.3 & 282.9 & 181.6 & 70.6 & 93.9 & 209.6 & 133.4 & 39.7 \\
\hline $\operatorname{ADL}(\% \mathrm{DM})$ & 11.1 & 19.9 & 15.4 & 3.5 & 7.2 & 15.5 & 12.0 & 3.1 \\
\hline
\end{tabular}


Table 2 Combustion TGA Results Showing Weight Loss (WL) and Peak Temperature (PT) for Each of Two Steps Along With Residue (RES) Data for Diet and Faecal Samples From the UoR and AFBI Trials. Minima, Maxima, Means and Standard Deviations are Presented.

\begin{tabular}{|c|c|c|c|c|c|c|c|c|}
\hline Parameter & Min & Max & Mean & Sdev & Min & $\operatorname{Max}$ & Mean & $\overline{\mathrm{Sdev}}$ \\
\hline & \multicolumn{5}{|c|}{ UoR Diets $(n=10)$} & \multicolumn{3}{|c|}{ AFBI Diets $(n=3)$} \\
\hline WL1 (\%) & 39.8 & 53.8 & 46.8 & 4.3 & 37.6 & 44.0 & 41.5 & 3.4 \\
\hline PT $1\left({ }^{\circ} \mathrm{C}\right)$ & 278 & 325 & 302 & 11.5 & 293 & 323 & 304 & 16.1 \\
\hline WL $2(\%)$ & 25.8 & 31.6 & 29.3 & 2.2 & 27.0 & 33.2 & 29.5 & 3.2 \\
\hline PT $2\left({ }^{\circ} \mathrm{C}\right)$ & 439 & 475 & 452 & 13.1 & 451 & 460 & 454 & 5.2 \\
\hline \multirow[t]{2}{*}{ RES $(\%)$} & 9.8 & 17.5 & 14.1 & 2.5 & 5.0 & 13.9 & 10.3 & 4.7 \\
\hline & \multicolumn{5}{|c|}{$\underline{\text { UoR Faeces }(n=10)}$} & \multicolumn{3}{|c|}{ AFBI Faeces $(n=12)$} \\
\hline WL 1 (\%) & 40.4 & 55.7 & 48.5 & 5.7 & 48.7 & 59.0 & 53.9 & 3.2 \\
\hline PT $1\left({ }^{\circ} \mathrm{C}\right)$ & 308 & 336 & 323 & 8.7 & 309 & 337 & 325 & 4.4 \\
\hline WL $2(\%)$ & 9.2 & 22.7 & 15.3 & 4.2 & 8.4 & 22.6 & 16.5 & 4.9 \\
\hline PT $2\left({ }^{\circ} \mathrm{C}\right)$ & 442 & 510 & 488 & 22.7 & 481 & 506 & 492 & 6.1 \\
\hline $\operatorname{RES}(\%)$ & 12.8 & 29.8 & 20.7 & 5.8 & 7.1 & 25.5 & 10.5 & 5.0 \\
\hline
\end{tabular}


Table 3. MaxRes Pyrolysis TGA Results Showing Weight Loss (WL) and Peak Temperature (PT) Individual Steps Indicated by Integer Along With Char Residue (RES) Data for Diet and Faecal Samples From the UoR and AFBI Trials. Minima, Maxima, Means and Standard Deviations are Presented.

\begin{tabular}{|c|c|c|c|c|c|c|c|c|}
\hline Parameter & Min & Max & Mean & Sdev & Min & Max & Mean & Sdev \\
\hline & \multicolumn{4}{|c|}{ UoR Diets $(n=10)$} & \multicolumn{4}{|c|}{ AFBI Diets $(n=3)$} \\
\hline WL1 (\%) & 9.5 & 17.1 & 12.4 & 2.0 & 10.8 & 12.6 & 11.8 & 0.9 \\
\hline PT $1\left({ }^{\circ} \mathrm{C}\right)$ & 212 & 257 & 248 & 13.1 & 207 & 260 & 242 & 30.0 \\
\hline WL2 (\%) & 10.4 & 24.3 & 18.0 & 4.5 & 13.7 & 21.9 & 16.8 & 4.4 \\
\hline PT $2\left({ }^{\circ} \mathrm{C}\right)$ & 262 & 293 & 285 & 8.8 & 261 & 291 & 281 & 16.8 \\
\hline WL3 (\%) & 7.2 & 18.4 & 9.9 & 3.3 & 6.2 & 19.9 & 14.0 & 7.0 \\
\hline PT $3\left({ }^{\circ} \mathrm{C}\right)$ & 293 & 322 & 314 & 8.2 & 291 & 338 & 312 & 19.4 \\
\hline WLA (\%) & 14.3 & 17.9 & 15.9 & 1.4 & 13.6 & 18.4 & 15.8 & 2.4 \\
\hline \multirow[t]{2}{*}{ RES (\%) } & 37.2 & 42.5 & 39.9 & 1.4 & 37.0 & 41.5 & 38.5 & 2.6 \\
\hline & \multicolumn{5}{|c|}{ UoR Faeces $(n=10)$} & \multicolumn{3}{|c|}{$\underline{\text { AFBI Faeces }(n=12)}$} \\
\hline WL1 (\%) & 12.8 & 19.1 & 15.0 & 2.2 & 11.9 & 17.2 & 14.9 & 2.0 \\
\hline PT $1\left({ }^{\circ} \mathrm{C}\right)$ & 282 & 294 & 288 & 3.8 & 278 & 287 & 282 & 2.4 \\
\hline WL2 (\%) & 11.6 & 22.2 & 17.1 & 3.8 & 11.0 & 20.6 & 16.8 & 3.3 \\
\hline PT $2\left({ }^{\circ} \mathrm{C}\right)$ & 310 & 326 & 318 & 5.5 & 306 & 318 & 312 & 3.2 \\
\hline WL3 (\%) & 6.6 & 9.2 & 7.7 & 1.0 & 7.3 & 14.1 & 10.1 & 2.6 \\
\hline PT $3\left({ }^{\circ} \mathrm{C}\right)$ & 349 & 358 & 354 & 3.7 & 340 & 347 & 342 & 2.2 \\
\hline WL4 (\%) & 12.6 & 20.0 & 16.2 & 2.9 & 13.6 & 16.4 & 15.0 & 0.9 \\
\hline $\operatorname{RES}(\%)$ & 39.6 & 53.7 & 45.7 & 4.9 & 37.1 & 48.1 & 41.0 & 3.5 \\
\hline
\end{tabular}


Table 4. Calibration $\left(\mathrm{R}^{2} \mathrm{c}\right.$, SEC) and Cross Validation $\left(\mathrm{R}^{2} \mathrm{cv}\right.$, SECV) Statistics for Prediction Models Developed From the Three Analytical Methods (FTIR, Conventional and MaxRes TGA). Calibration Performance was Measured by Calculation of the RPD Value.

\begin{tabular}{|c|c|c|c|c|c|c|}
\hline \multirow[b]{2}{*}{ Method } & \multirow[b]{2}{*}{$\mathrm{n}$} & \multicolumn{2}{|c|}{ Calibration } & \multicolumn{3}{|c|}{ Cross Validation } \\
\hline & & $\mathrm{R}^{2} \mathrm{c}$ & SEC & $\mathrm{R}^{2} \mathrm{cV}$ & SECV & RPD \\
\hline FTIR & 35 & 0.97 & 1.42 & 0.89 & 2.52 & 2.20 \\
\hline Conventional TGA & 35 & 0.98 & 1.08 & 0.94 & 1.84 & 3.05 \\
\hline MaxRes TGA & 34 & 0.98 & 1.17 & 0.95 & 1.64 & 3.38 \\
\hline
\end{tabular}


Figure 1. To be published in colour

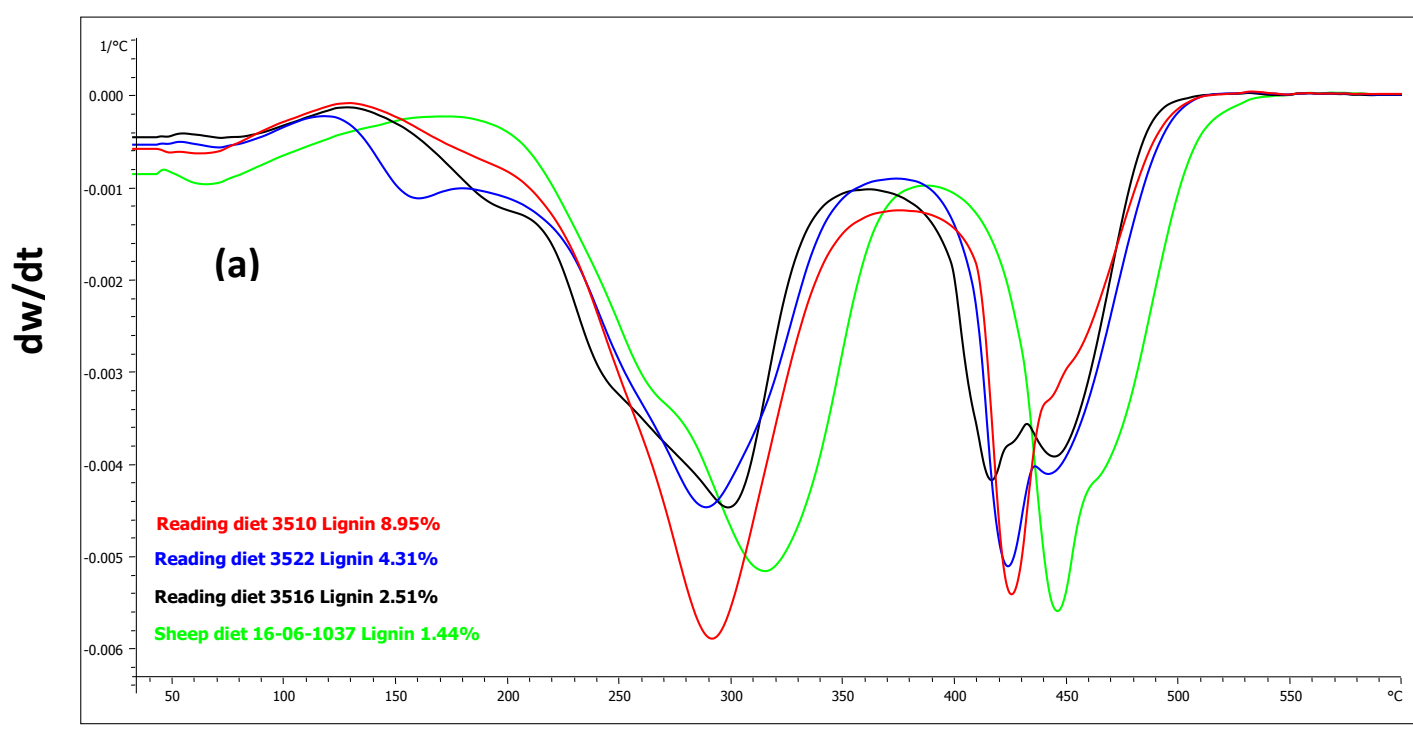

Temperature $\left({ }^{\circ} \mathrm{C}\right)$

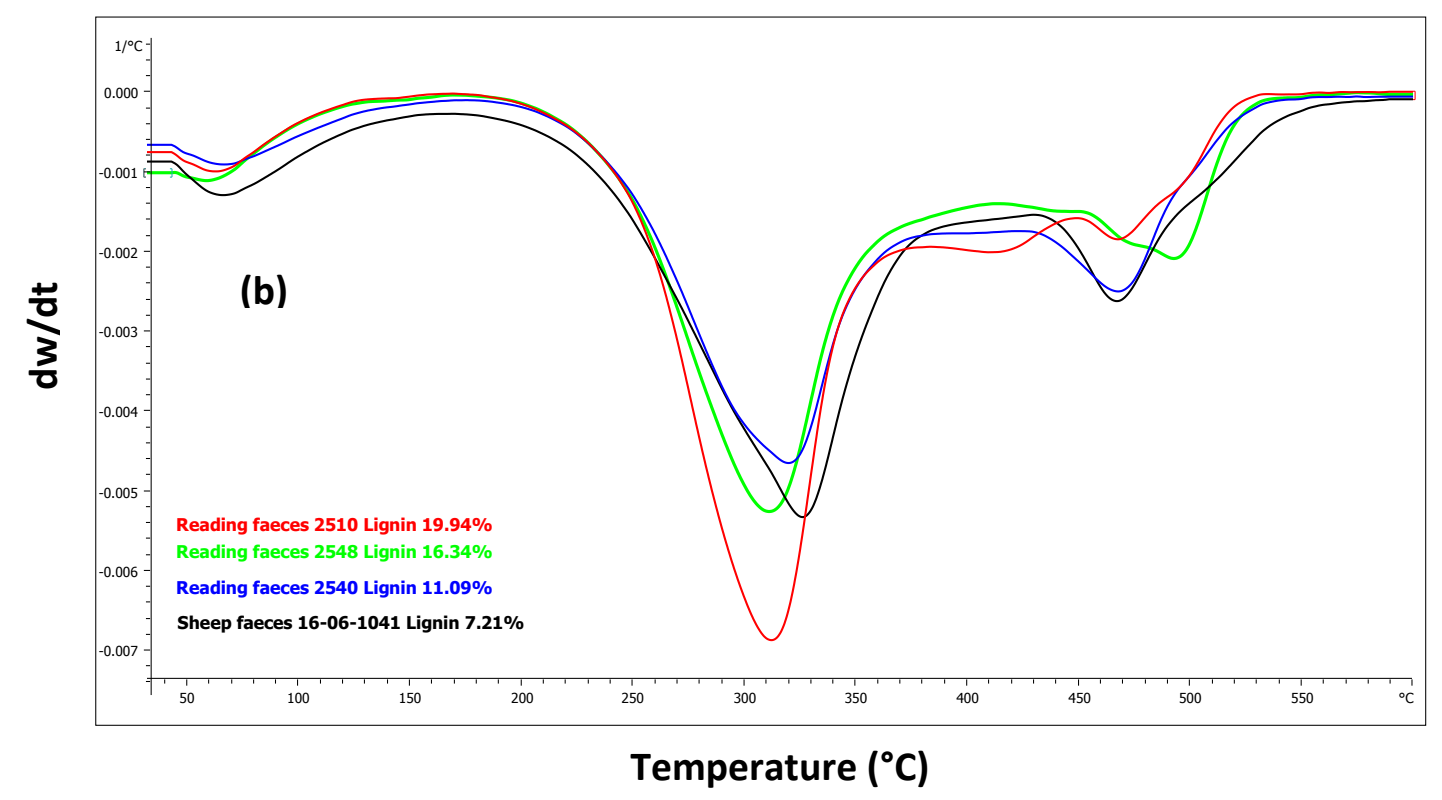


Figure 2. To be published in colour

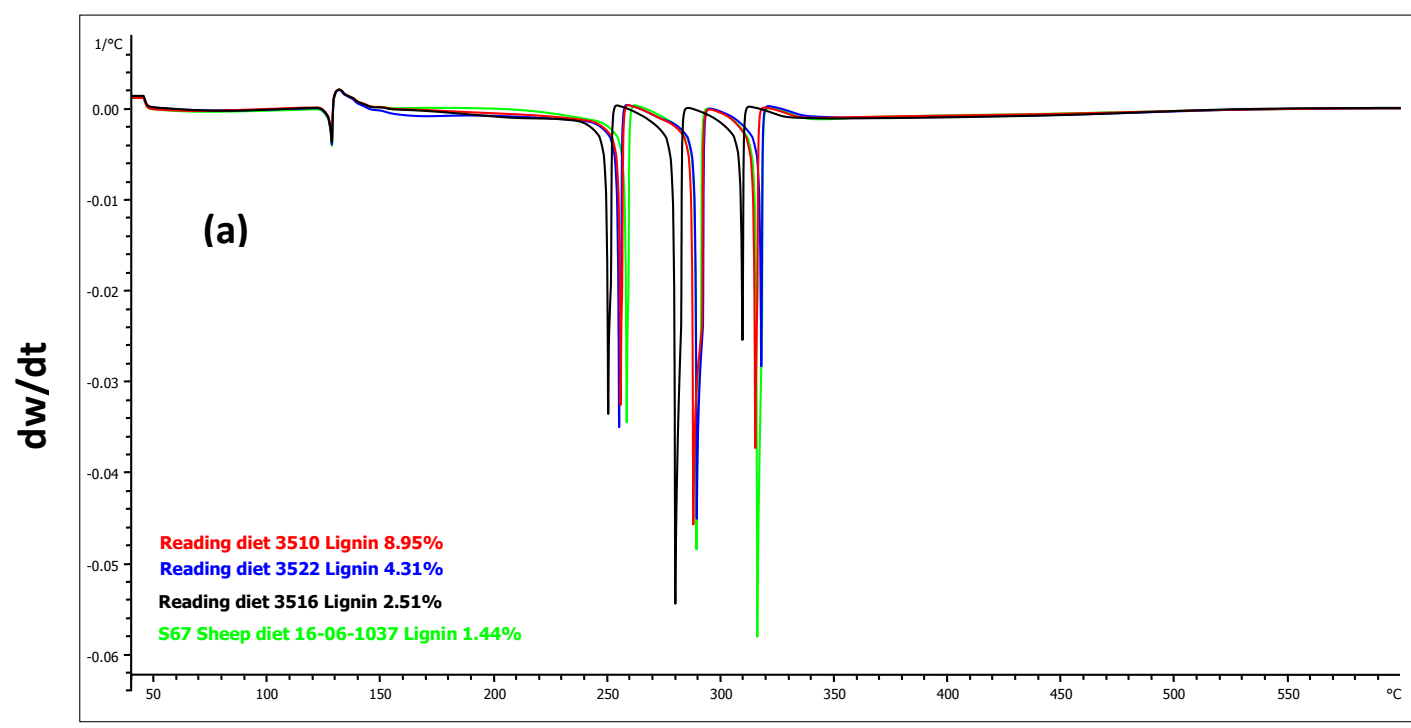

Temperature $\left({ }^{\circ} \mathrm{C}\right)$

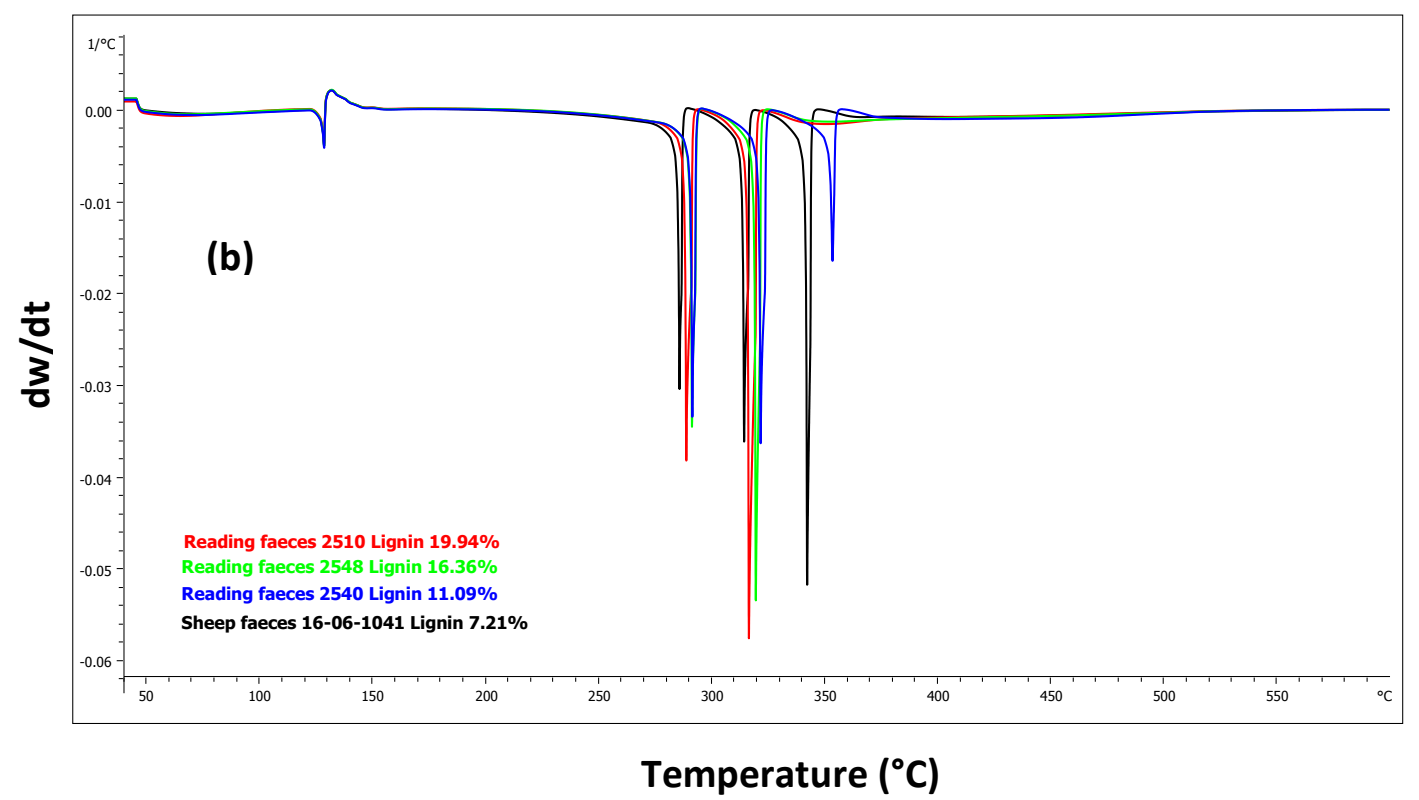


Figure 3. To be published in colour
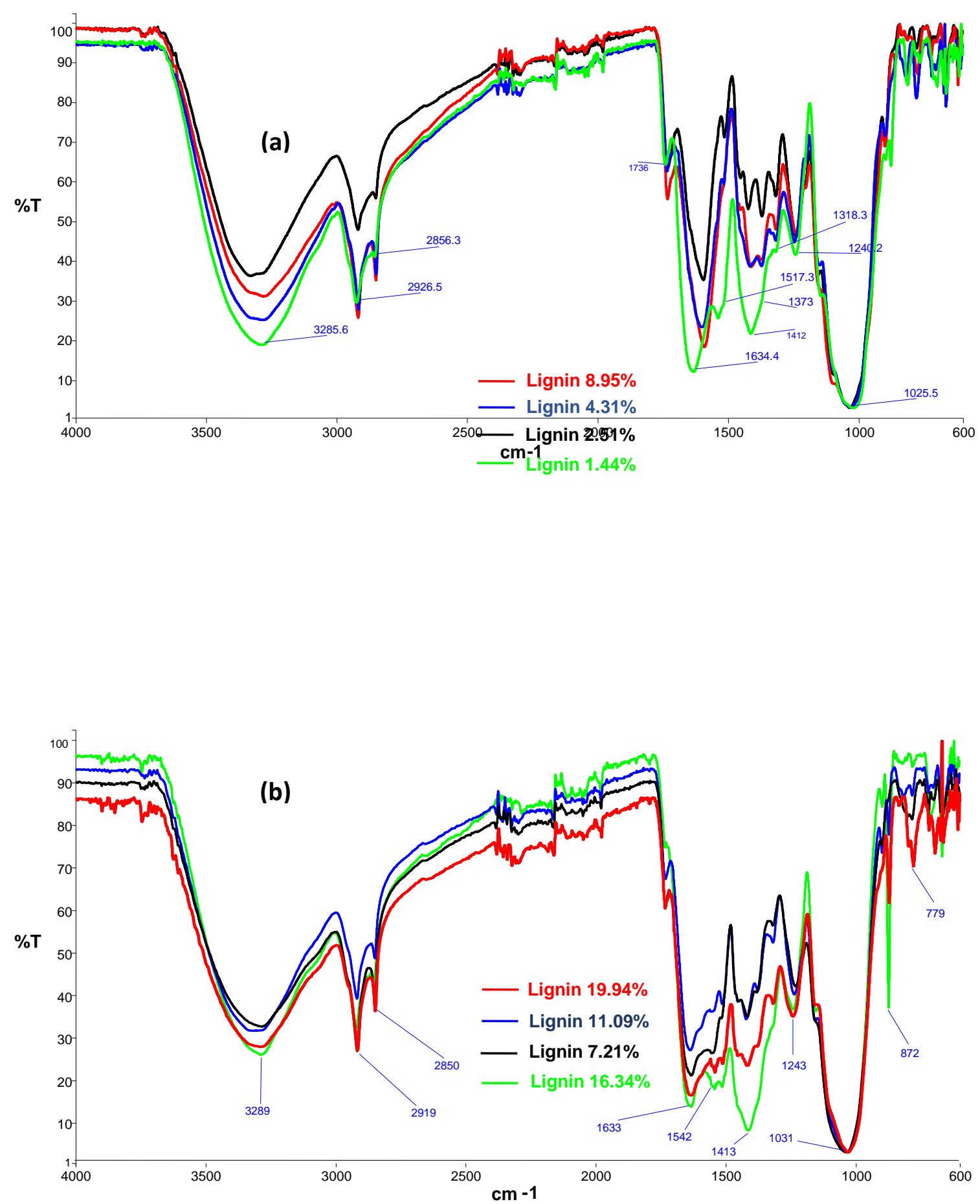
Figure 4.
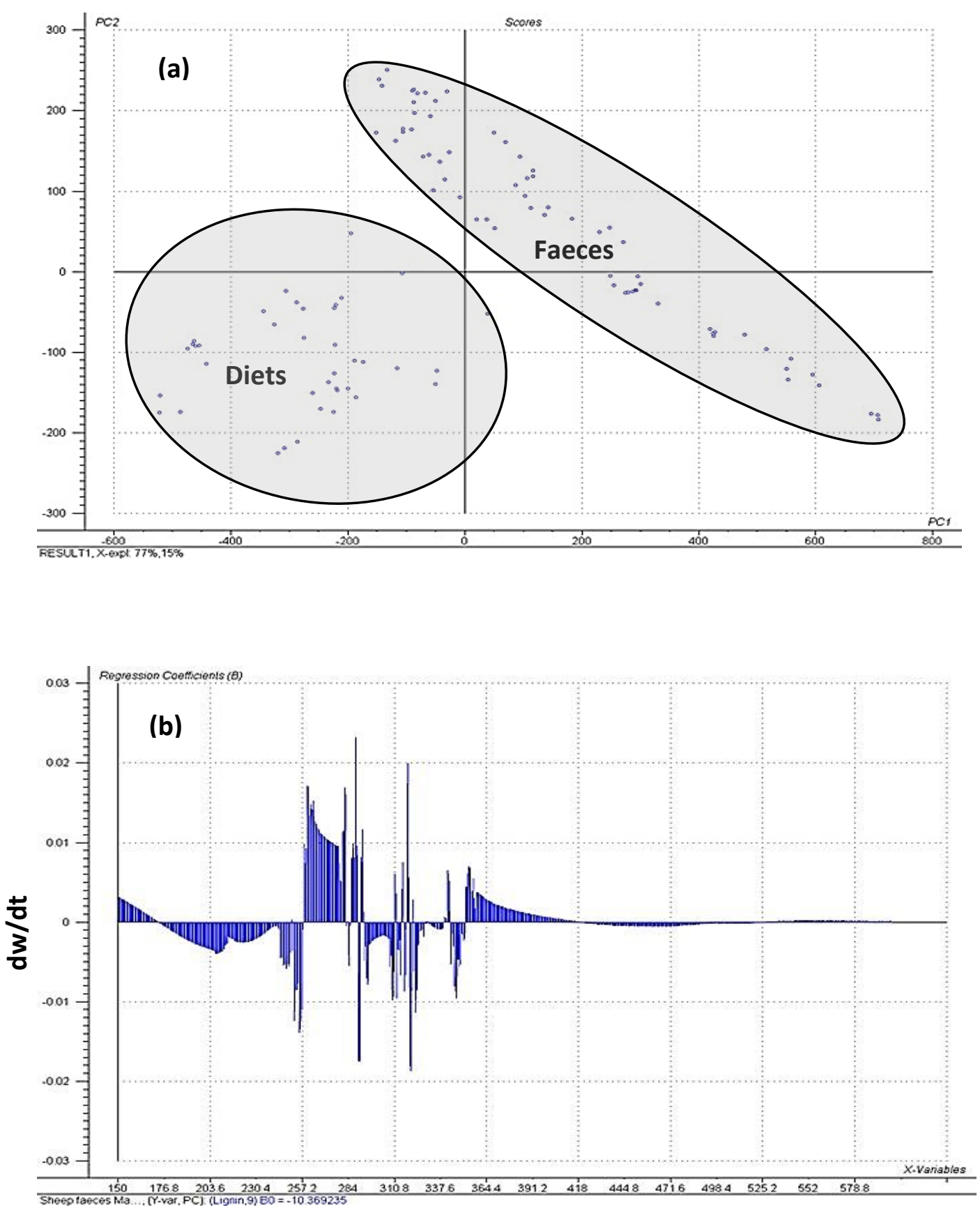

Temperature $\left({ }^{\circ} \mathrm{C}\right)$ 


\section{TOC Graphic}

Prediction of lignin content in ruminant diets and faecal samples using rapid analytical techniques.

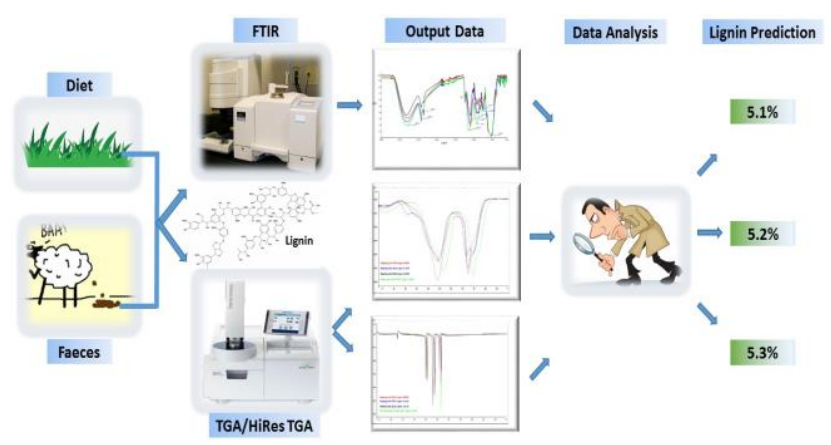

TOC categories:

1. Analytical Methods

2. Agricultural and Environmental Chemistry

3. Biofuels and Biobased Products 